\title{
A Manual Well Drilling Pilot Project: Implementing the Water for All International Method
}

\author{
Alison M. Forsyth, Eshwan Ramudu, Helen Louise Hindal, and Dana R. Lazarus \\ School of Engineering and Applied Sciences \\ Harvard University \\ Cambridge, MA 02138 \\ amforsyt@fas.harvard.edu
}

\begin{abstract}
A manual well-drilling pilot project based on the Water for All International drilling method was undertaken in a small rural community in the Dominican Republic. Water testing for determining the level of biological and chemical contaminants was used to better assess the water needs of the community. For geophysical exploration, an experimental resistivity method and survey of existing wells provided information to better optimize the drilling location. With this information a pilot well site was selected in Tireo Abajo, and over the course of a week a 9 meter-deep well was successfully drilled, cased, and conditioned. The partner family and as many as $\mathbf{4 0}$ other members of the community helped to develop and implement this method during every stage of the process. This suggests the potential for a long-term development project that could benefit their community.
\end{abstract}

Index Terms - Water for All International, Dominican Republic, water, manual well-drilling, well conditioning

\section{BACKGROUND}

Access to clean drinking water is considered to be a basic human right. One of the eight millennium development goals set by the United Nations to alleviate human suffering is to "halve, by 2015, the proportion of people without sustainable access to drinking water." Governments and leading development organizations have been implementing sustainable and cost-effective methods to address the water issue, but problems persist. According to the World Health Organization, more than 884 million people still lack access to safe water, a humanitarian crisis, which, combined with poor hygiene in developing countries, kills over 1.5 million children each year ${ }^{\mathrm{i}}$.

Harvard College Engineers without Borders (HCEWB) was founded in the Spring of 2007 by undergraduate engineering students with the goal of working on sustainable community-driven projects to improve the quality of life in developing countries. Shortly thereafter, HCEWB was approached by physicians from the Massachusetts-based St. Jerome's Parish Constanza Mission. Since 2007, the physicians have been making biannual week-long trips to the rural community of Tireo in the Dominican Republic. These doctors practice in a local clinic during their trips and 
reported a prevalence of water-related illnesses, including diarrhea and parasites. They asked HCEWB to investigate the local water supply in order to provide a permanent solution to the community's health problems.

Tireo is a rural town approximately six miles by road from the city of Constanza in the La Vega province of the Dominican Republic. It consists of more than 1200 houses in eight subcommunities, with an average of five persons per family. Six of the eight sub-communities receive water intermittently from a treatment facility with a non-functional slow-sand filter under the supervision of the Instituto Nacional de Aguas Potables y Alcantarillados (INAPA).

HCEWB completed a preliminary assessment trip in the area on November 8-12, 2007, to survey family health and hygiene practices, explore local water sources and treatment facilities, and meet with water administrators, community leaders, and local families. The team identified two main problems relating to potable water supply in the area: first, that the water passing through the treatment facility was not potable; and second, that the water supply did not adequately serve the community. They also observed that due to the intermittent supply of water, a consequence of the limited capacity of the treatment facility and distribution network, households were forced to store water for later use, which led to increased contamination due to improper hygiene practices.

Following the preliminary assessment trip, HCEWB took two approaches to the water problems in Tireo. One HCEWB team began investigating ways to work with INAPA to improve the water filtration and distribution system for those receiving water from the treatment facility. This project also focused on educating the community about proper water storage and hygiene. A second project, and the focus of this paper, began a small scale project to create a supply of potable water for those not connected to the larger system. In developing this project, our group took into account several factors such as economic development environmental protection, and social development, which are defined to be three main pillars of sustainability. ${ }^{\text {ii }}$

\section{A Small-Scale Project to Provide Access to Potable Water}

Tireo Abajo, a community of approximately 75 people, is one of the more distant subcommunities of Tireo. Homes in this area are not connected to the water distribution system, and, lack access to a water supply. Those who can afford to purchase bottled water do so; however, most are forced to drink from polluted streams or existing unprotected and contaminated wells. Connecting Tireo Abajo to the INAPA system was not pursued for three reasons: first, the system is currently not providing potable water; second, the capacity of the system is already below demand from connected communities: and last, it would have required more than $10 \mathrm{~km}$ of piping as well as an intra-community distribution system, which we felt was beyond our capabilities.

An assessment trip on May 24-31, 2008, provided an opportunity for the HCEWB team to meet with local people and discuss water supply issues and potential sources of potable water. Upon initial meetings with local community members, we were told that seasonal variation in precipitation made rain catchers an unfavorable solution for this rural community. Protecting current surface water sources with spring boxes was ruled out after our assessment trip showed 
that these sources were high in the mountains, requiring a vast distribution system to protect the water until it could be made accessible to the community. The containment and protection of existing wells in the area, which were all found to be unprotected and close to contamination sources, has not been fully ruled out and may be focused on in the future. However, even if they were potable, these wells could not supply enough water for the entire community, and therefore we found that new sources were necessary.

It is our belief that household access to ground water can alleviate both the supply and storage problems which plague Tireo Abajo. A well drilling project also provides access to groundwater, which generally has a drastically decreased risk of contamination compared with surface water. ${ }^{\text {iii }}$ In order to begin planning our future trips, we had to decide whether to focus on smaller, family-sized wells or larger community wells.

Manual well-drilling, technically borehole-drilling, typically provides 50-100 $\mathrm{mm}$ diameter wells that are designed to sustain families. These wells provide the advantage that they can, in the right hydrogeological conditions, be drilled with minimal technology and cost. Conversely, larger community wells require increased technology and cost to drill deeper and larger holes, but could provide water for the entire community with a single well. Large-scale wells have another drawback in that they are susceptible to contamination from their many users. This risk is reduced with family-sized wells because of the lower number of users and the clear responsibility for maintenance and upkeep. If a large scale well becomes contaminated the entire community is affected, rather than a single family, while no person or family feels responsible for it. Finally, a community well requires family members to commute to and from the source a task that we anticipate would be done by women and children. Putting the well close to the home reduces time spent transporting water, and reduces the need for storage. It is noted that this selfsupply approach has been found to offer greater sustainability, improved water quality, and opportunity for growth of the rural economy and of individual households. ${ }^{\text {iv }}$ For these reasons, a family-sized manual well drilling pilot project was pursued.

During the May 2008 trip, the HCEWB team was able to procure supplies, find a local family who was interested in helping to build a pilot well, and begin construction of the drilling rig itself. Local residents were very excited about the possibility of a well drilling project. The next trip on January 23-27, 2009, saw the completion of the pilot well. The goal of these trips was to evaluate and explore the potential for a long-term manual well drilling project in the area. Currently, steps are being taken to evaluate if this is best way to increase the supply of water for Tireo Abajo and to develop a project into a long-term solution. Accounting and allocating responsibility for the true costs of sustainability is an especially important aspect of our project and one that our group is looking into to develop this project over the long term. ${ }^{\mathrm{v}}$

\section{Manual Well Drilling Methods}

Once small, family-sized wells were chosen as a possible solution to the water supply problem in Tireo Abajo, several inexpensive drilling techniques were investigated: well point driving, hand augers, percussion drilling, and sludge drilling. 
The first method we considered using was well point driving. With this method, a sharp point made of a porous material is attached to the end of a pipe that is driven into the ground with a fence-post pounder. Once the desired depth is reached, the pipe remains as the well casing and the porous well point serves as the filter. Well point driving is limited to drilling wells a few meters deep without heavy equipment and was not explored further because of this limitation.

Another method uses hand augers: steel rods with large plate bits on the bottom. The auger is rotated in the ground and then removed from the hole in order to remove the cuttings from the bit. Operated by hand, the auger method is limited to a depth of $10 \mathrm{~m},{ }^{\mathrm{vi}}$ but with the help of a tripod and winch using a similar auger bit, this method can reach up to $25 \mathrm{~m}$. ${ }^{\mathrm{vii}}$ This method is very labor intensive by hand and has an increased risk of borehole collapse because drilling fluid is not used. In addition, hand augers are not able to drill through consolidated layers. ${ }^{\text {viii }}$

A third method is percussion drilling, a method that allows a heavy cutting tool to be dropped via a cable attached to a tripod or derrick. The drill bits are designed to displace or cut into the soil, filling a large cylindrical bit known as a bailer that is then emptied at the surface. The bailing percussion method is more efficient than the auger but still has the disadvantage of not using drilling fluid to prevent the hole from collapsing. Also, while the bit displaces soil in this process, it simultaneously consolidates the soil below, slowing progress. A percussion method does, however, have the ability to slowly drill through medium strength formations. ${ }^{\text {ix }}$

Sludge drilling requires drilling fluid and a long pipe that is moved up and down in the drilling hole. On the down-stroke the force of the pipe loosens the soil on impact while on the up-stroke the inertia of the fluid brings these soil cuttings up above the ground. This method is advantageous in that it uses drilling fluid to prevent borehole collapse and is efficient at drilling through silt and sand. However, it requires a water supply and the use of sludge makes it difficult to predict when the water table has been reached. ${ }^{\mathrm{x}}$

The Water for All International method (WFAI), sometimes referred to as the "Baptist" method, was developed by Terry Waller, who is based out of San Angelo, Texas and Eastern Bolivia $^{\mathrm{xi}}$. The method relies on a hybrid of sludge and percussion drilling technology ${ }^{\mathrm{xii}}$ to drill boreholes up to $105 \mathrm{~m}$ deep. ${ }^{\text {xiii }}$ With a specialized drill bit and a tripod or derrick system, the WFAI method combines the advantages of percussion drilling, such as being able to drill through light rock $^{\mathrm{xi}}$, with the high efficiency of sludge drilling in unconsolidated layers.

WFAI's implementation of this technology relies on a bottom-up approach. Well drilling clubs are formed that borrow or purchase drilling rigs and drill wells for all club members under the guidance of WFAI. The premise behind the project is to empower individual families to obtain and maintain their own water supply. Although this type of project may not reach as many people as a large-scale water distribution system, it puts control over the vital resource of water into the hands of the individual. This method is currently being developed in 16 countries and has been used to drill approximately 2,000 wells. ${ }^{\mathrm{xv}}$

We recognize that well drilling is a high-risk venture because of the time-intensive nature of the process and the uncertainty inherent in groundwater exploration, and that this method is not appropriate for all communities because other clean water options detailed above are available. However, we believe that the benefits of a protected water supply in near proximity to a household with clear responsibility for upkeep outweigh the time investment for the Tireo Abajo community.Cost of this method was an important reason for this logic. Our WFAI drilling rig and pilot well was 550 USD, however, the drilling rig, which is re-usable, was approximately 400 USD of the total value. With greater knowledge of local materials and expertise this cost can be 
reduced in the future. One of the existing family-sized wells in Tireo Abajo cost 2,000 USD (later referred to as Alejandro's well).

\section{A Service Learning Project}

A final consideration in choosing this project as a water supply solution was the potential benefit to student members of HCEWB. This project involves hands-on design and implementation based on engineering principles. We believe that this project provides students with the opportunity to augment their education by taking ideas that they learn in the classroom and transforming them from paper to developing-world infrastructure solutions. The small-scale nature of this allowed students to get their hands dirty, quite literally.

Through this project, students were also able to interact directly and extensively with local families throughout the well drilling process, resulting in a cultural exchange. The community educational component of this project, specifically regarding water storage, hygiene, and the drilling method was largely informal during these short assessment trips. During the early stages of the project, we felt it was best to meet as many people as possible in order to raise awareness in the community about the water supply and to solicit local people advice about manual well drilling as a possible solution. It was our perspective that we needed to build a relationship with the community before beginning a formal education program.

\section{METHODS}

\section{Trip Preparation}

For our final assessment trip in January 2009, seven members--six undergraduates ranging from first to fourth year and one graduate student--of the HCEWB team were selected to travel based on earlier contributions to the project, specific expertise in pump design or resistivity surveys, language skills, and group dynamics. There was no minimum level of education, and our group numbers at that time prevented us from only taking more senior students. All students on the trip were studying engineering, although this was not a prerequisite for the trip and HCEWB draws students from a variety of academic specialties.

All pre-trip organization was done by students, under the guidance of a faculty advisor, and no college credit was available for participation. A member of WFAI, Alan De Laurell, accompanied us on the trip to provide pratical insight into the drilling method beyond what we had learned from the WFAI materials. No "practice" drilling took place before our trip because geological conditions and available material are so different between the two regions. Trip members were required to read extensively about the drilling method, and implementation methods were reviewed in detail. Funding was obtained thanks to the efforts of an HCEWB committee responsible for grant writing. The bulk of the funding was received from: Harvard School of Engineering and Applied Sciences, General Motors Sullivan Grants, and Harvard College Research Program.Students going on the trip were asked to contribute a small portion of the cost to confirm their commitment to the trip and for financial assistance.

Through the aid of the doctors of the Massachusetts-based St. Jerome's Parish Constanza Mission, trip members were introduced to community leader Sor Rosario, a nun in the local parish. She provided help with accommodation, food, and transportation and was an invaluable 
asset. Through her we were introduced to members of Tireo Abajo and began speaking with local leaders and community members interested in the project. Local Peace Corps volunteers also worked as liaisons and translators, providing cultural insight and contacts for the development of a long-term project.

\section{The Community Connection}

The goal of our pilot well was to partner with a family in Tireo Abajo to drill a well that would provide drinking water and, if successful, act as a stepping-stone from which to launch a larger scale project. However, we recognized that it was possible we would not be successful at implementing the WFAI drilling method during the trip. As such, we approached the local community with perspective that we had an idea, but that we would need their help and expertise to make the method work. For these reasons, the family was only expected to donate their time, while HCEWB provided the financial means for the drilling rig, well casing, and hand-pump, worth approximately 550 USD total. The family acted as local ambassadors for the project, spreading the word to get community members excited and identifying other families who might be interested as the project expands. Through the help of local Peace Corps volunteers, who have a sustained presence in the community, we hope to be able to eventually turn this well-drilling method into local knowledge through a combination of continual visits from HCEWB and constant on-the-ground support from the Peace Corps volunteers.

\section{Site Exploration}

Our choice for the location of the well was based on several considerations. First, we observed the physical geological features of the area. Most inhabitants of Tireo Abajo reside in a valley through which flows a wide, shallow river known as Rio Tireo. Agricultural fields and topsoil indicated an abundance of red clay in the soil. However, the surface rocks and the river bank layout suggested large concentrations of unconsolidated sediments such as sand and gravel beneath the clay.

We located five other wells in Tireo Abajo and recorded their head, approximate depth, diameter, location, and water quality. This information helped us to estimate how deep the water table would be at different potential drilling sites based on the head in each of these wells and their elevations in relation to the river. Care was taken to follow precautions and ensure that our well site was more than $10 \mathrm{~m}$ from any uphill latrines or possible animal contamination sites, and that no obvious sources of contamination were in the near vicinity of the well site. ${ }^{\mathrm{xvi}}$

Our drilling site was chosen for its location at approximately $6 \mathrm{~m}$ above the Rio Tireo, minimizing the distance that had to be drilled to reach the water table. In order to gain more insight into the underlying geophysical environment and delineate the main soil types in the region, different survey methods such as resistivity, electromagnetic wave sounding, groundpenetrating radar, and seismic refraction were investigated. ${ }^{\text {xvii }}$ We chose the resistivity survey because it is non-destructive, inexpensive, and allows for a coarse interpretation of the ground conditions by comparing the results obtained with reference results. ${ }^{\text {xiii }}$ The Resistivity method indicates how the resistivity and hence water content of the soil changes with depth.

Four rebar steel electrodes of length $1 \mathrm{~m}$ and diameter $63.5 \mathrm{~mm}$, a 12-V, 2.3 Ampere-hour battery, and a multi-meter were used. The electrodes were arranged in a Schlumberger array, consisting of two potential electrodes (connected to the battery) and two current electrodes 
(connected to the multi-meter). The two potential electrodes were placed at a distance of about 1 $\mathrm{m}$ apart, and the current electrodes were moved away from the mid-point of the line joining the two potential electrodes in regular steps up to a separation of $50 \mathrm{~m}$. The resistance was measured and multiplied by a geometric factor $K_{r}$, ${ }^{\text {xix }}$ which depends on the arrangement of the four electrodes, to give the nominal resistivity. ${ }^{\mathrm{xx}}$

\section{Drilling Method}

Once a suitable location was chosen, a one meter hole approximately $10 \mathrm{~cm}$ in diameter was dug with a shovel and by hand. During the first $4.5 \mathrm{~m}$ of drilling, care was taken to ensure that the borehole remained as straight as possible in order to prevent drilling into the ground at an angle, and preventing further progress at greater depths. To this end, the first $3 \mathrm{~m}$ were drilled by hand using the regular drill bit and drilling stem, without the assistance of the tripod.

A tripod was constructed using $5 \mathrm{~cm} \times 10 \mathrm{~cm}$ planks (standard American 2 x 4's) nailed together to make three $4.5 \mathrm{~m}$ poles two planks thick. The three poles were joined at the top using figure of eight frapping and nails were used to prevent the rope from sliding. The tripod legs were rotated to prevent the nails from popping out when the poles bent under weight (Figure 1A). The legs were arranged in an $X$ formation such that the centre pole was supported by the other two, and a $\sim 7 \mathrm{~cm}$ pulley was hung from the centre pole to ensure maximum stability (Figure 1B). A rope was run through the pulley and tied to the drilling stem with two clovehitch knots on one end, and a wooden handle on the other (Figure 1C).

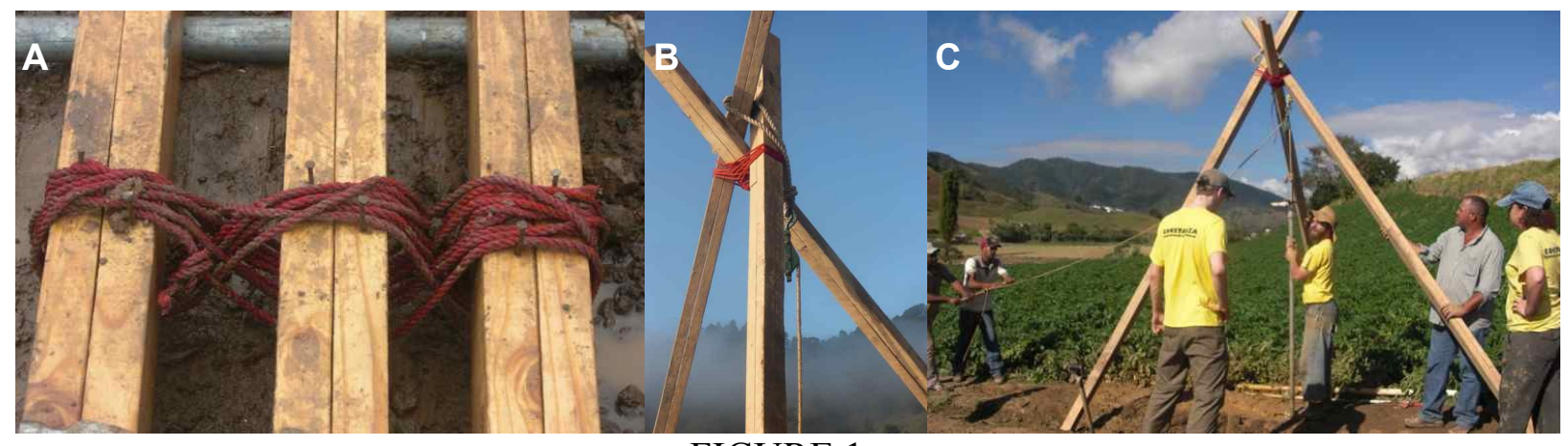

FIGURE 1

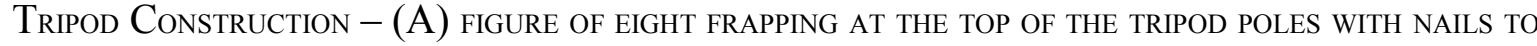
PREVENT SLIDING (B) X FORMATION SUPPORTING the CENTRE, WEIGHT-BEARING POLE (C) TRIPOD STANDing AND LEVEL WHILE DRILLING IS IN PROCESS.

The drilling stem was made of $32 \mathrm{~mm}$ galvanized steel pipe. The first segment was $3 \mathrm{~m}$ long and the next two segments were each $1.5 \mathrm{~m}$ long. The segments were attached together using cast iron couplings and a standard pipe wrench as drilling progressed. Galvanized steel was used for the first $6 \mathrm{~m}$, after which lengths of $25 \mathrm{~mm}$ PVC were added to the top of the drilling stem. This design reduces the weight of the stem and allows for manual drilling to greater depths. PVC couplings typically have conical threads in this region, leading to gaps when they were combined. Spacers reduced the stress concentration at these junctions. The reducing coupling between the $32 \mathrm{~mm}$ steel pipe and the $25 \mathrm{~mm}$ PVC pipe had a metal nipple so that the first PVC coupling was female. 
The drill bit was attached to the bottom of the drilling pipe via a coupling. This bit acts as a one-way valve: closing while the drilling pipe is suspended and opening when the pipe is dropped. In this way, cuttings and mud were forced into the drilling pipe and expelled at the top of the pipe during the peak of the up-stroke. In order to eject mud from the top of the pipe a frequency of $\sim 1 \mathrm{~Hz}$ needs to be maintained, with quick short strokes approximately $1 \mathrm{~m}$ being most effective.

The borehole was full of drilling fluid throughout the entire process, which is mixed from locally available clay. A settling pit was dug in front of the stem to catch some of the ejected mud and allow it to flow back into the borehole. The drilling fluid increases the pressure in the borehole and adheres to the sides of the hole; both prevent the hole from collapsing during drilling. Note that bentonite was not available in the region, and is not recommended for use in manual drilling because of its excessive adhesion on the wall formation which can be difficult to remove $^{\mathrm{xxi}}$. We were pleased with the clay's ability to prevent collapse; when drilling through coarse sand more clay was added to the drilling fluid. The clay content of the soil was tested by squeezing a small amount into a ball. The higher the clay content in the soil the better the ball holds its form.

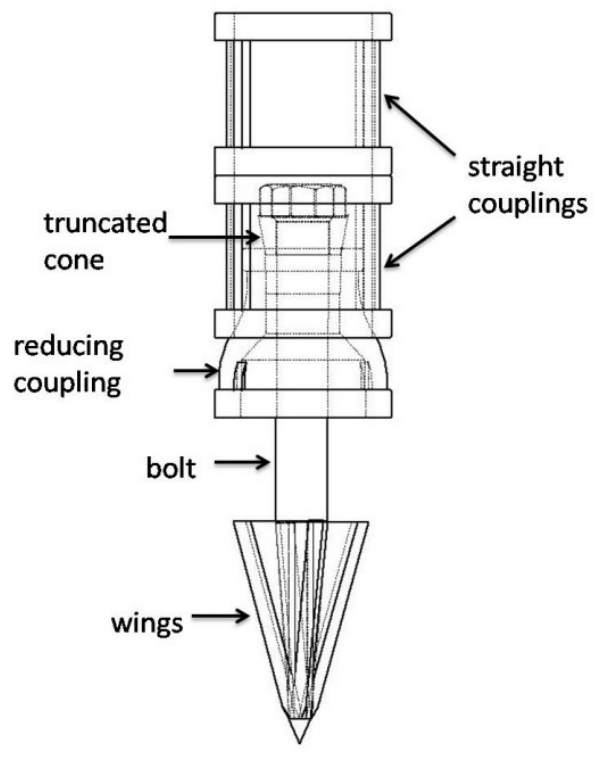

\section{FIGURE 2}

Schematic of the Wfai drill bit used in the dominican RePublic. A Steel bolt With four Wings Welded TO IT SITS INSIDE A REDUCING COUPLING PRODUCING A ONE-WAY VALVE AT THE BOTTOM OF THE DRILLING STEM.

The bottom pipe of the drill bit (Figure 2) was made by welding 3, $32 \mathrm{~mm}$ high pressure couplings together. The top 2 couplings were straight, while the bottom one was a $32-25 \mathrm{~mm}$ reducing coupling. Inside the reducing coupling sits a $1.58 \mathrm{~cm}$ bolt that was cut to be approximately $12 \mathrm{~cm}$ long, and was grinded into a sharp cone on the bottom. Around the top of the bolt, extra filler has been welded to make a truncated cone. 4 sharpened wings $7 \mathrm{~cm}$ in height and $1.5 \mathrm{~cm}$ at the maximum width made from leaf-spring were welded onto the bolt. The top coupling can thread onto the bottom of the drilling stem. 


\section{Well Casing \& Conditioning}

Once drilling has ceased, a well must be cased and then conditioned. Casing the well involves the placement of a PVC pipe with a filter at the bottom into the borehole to prevent the hole from collapsing once the drilling fluid is removed. Conditioning refers to the removal of drilling fluid from the walls of the hole, known as the formation, and the removal of smaller particles from around the filter in an effort to increase flow horizontally (recharge rate) into the well.

Based on our site exploration and surveys of pre-existing wells in the area, at a depth of $\sim 9$ meters we ceased drilling and began to case the well. From our survey we predicted that we would reach the water table in approximately $4.5 \mathrm{~m}$. At a $9 \mathrm{~m}$ depth, the drilling stem was removed and a $40 \mathrm{~mm}$ PVC casing with a $1.5 \mathrm{~m}$ filter at the bottom was inserted. Drilling was stopped due to time constraints but it would have been advantageous to continue drilling to greater depths and to ream (repeat the drilling process with a larger drill bit) the hole to a larger diameter, both processes would have increased the well's water yield. Additionally, deeper wells have a greater chance of producing potable water, as there is a lower chance of contamination from surface water and a better ability for the soil to naturally filter the water.

Before drilling was complete, the filter was constructed by making even horizontal cuts on both sides of a $40 \mathrm{~mm}$ pipe approximately $1 \mathrm{~cm}$ apart (Figure 3A), and then wrapping and gluing a new potato sack to the filter (Figure 3B), as described in the WFAI drilling manual ${ }^{x x i i}$. The potato sack serves as a permeable, flexible material that can prevent larger sand particles from entering into the well. In choosing an appropriate potato sack, permeability must be weighed carefully in order to ensure adequate flow into the well but prevent sand infiltration. Next, 40 $\mathrm{mm}$ PVC pipe segments, starting with the filter, were cemented together as they were inserted into the hole. To counteract the buoyancy of the casing, the pipe was filled with water while it was pushed into the hole. Once the casing was fully inserted, it was staked to the ground using tire tube rubber, called goma locally (Figure 3C).

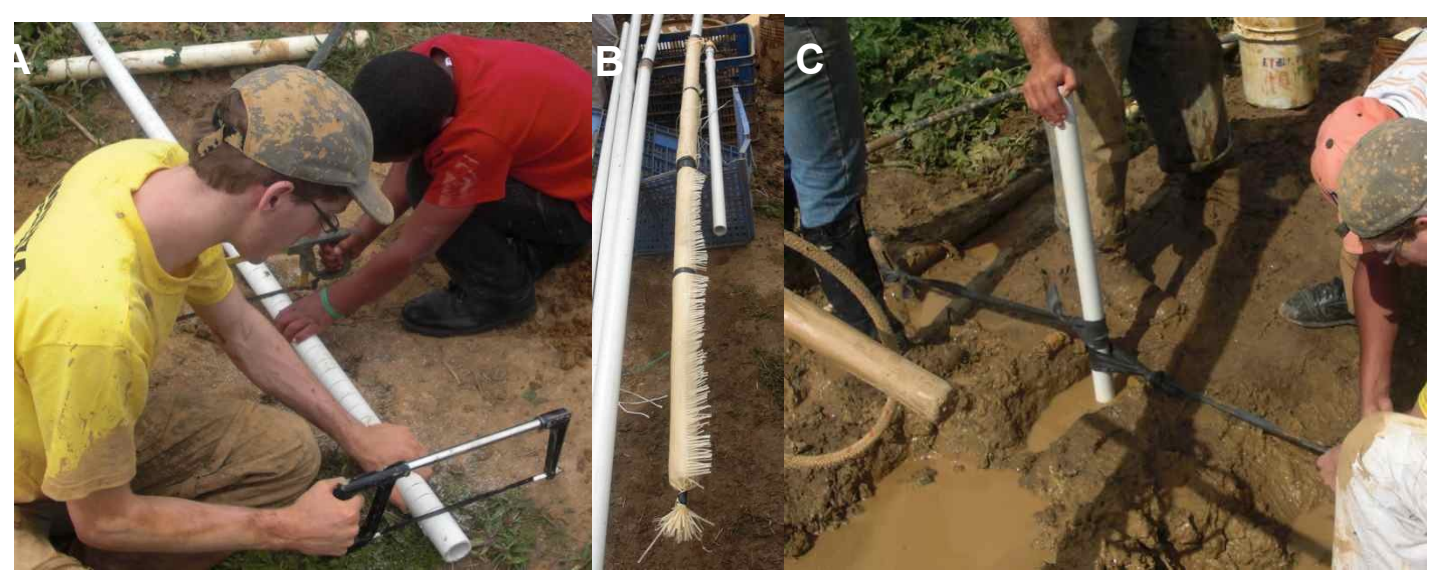

FIGURE 3

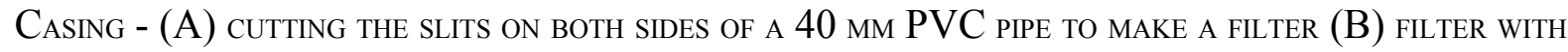
the potato sack Wrapped one fUll TURN around the pipe (C) HOLDing the Casing IN PLACE With GOMA AND STAKES UNTIL CONDITIONING WAS UNDERWAY. 
The well was then conditioned, first by back-pumping water into it (Figure 4A). This process forces water down through the casing, out the filter, and up along the outside of the casing between the casing and the formation. This cleaned the drilling fluid that had adhered to the formation, allowing the walls of the hole in the unconsolidated regions of the ground to collapse around the casing, a process which takes only a few minutes. Due to the close proximity of the river, we used an irrigation water pump to inject water into the well rather than pumping by hand. Dirty water can be used for conditioning because much larger volumes of water were pumped from the well, removing possible contaminants. ${ }^{\text {xiii xxiv }}$ As an extra precaution the well was bleached before sealing.

To continue conditioning water was removed from the well with an inertia pump consisting of a $14 \mathrm{~m}$ long, low-density polyethylene $20 \mathrm{~mm}$ tubing with a check valve at one end (Figure 4B). Electrical tape was wrapped around the check valve, so that the valve was just smaller than the casing. The tubing was lowered into the well casing until the check valve hung at the level of the filter. Taking long vertical strokes with the inertia pump, it was possible to remove sandy water from the bottom of the well. This motion acts to pull sand and small particulate out of the formation, in the region surrounding the filter, the opposite action of back-pumping. Blocking the top of the inertia pump, a process known as swabbing can also enhance conditioning by forcing water to circulate around the check valve. By repeating the back-pumping, inertia pumping, and swabbing steps several times the formation was slowly conditioned, creating small pathways for the water to flow toward the well, and increasing the recharge rate of the well.

A

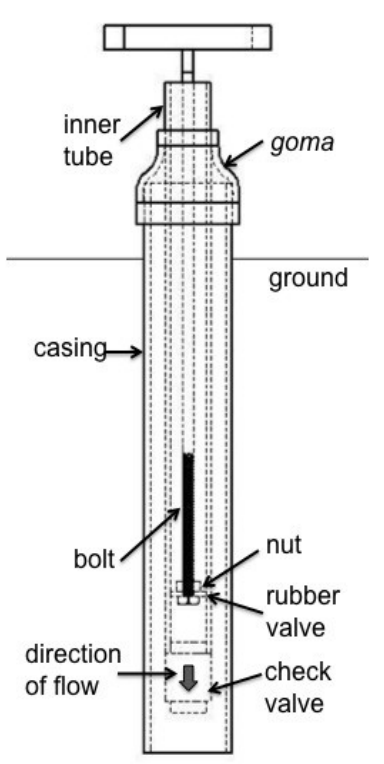

B

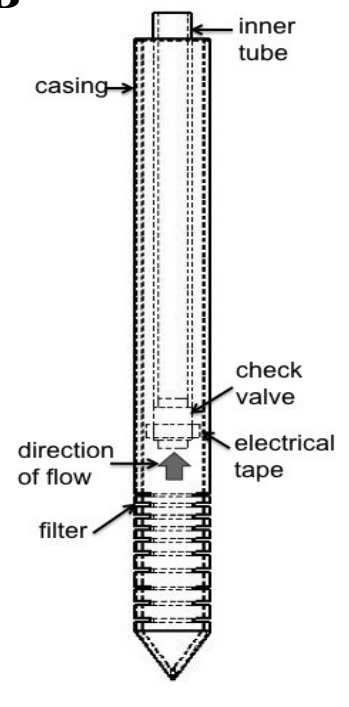

FIGURE 4

Pumps - (A) Back Pump schematic With Length truncated to Show detail and ground Level. The BOTTOM CHECK VALVE AND TOP RUBBER SEALER ONLY ALLOW WATER TO FLOW DOWN INTO THE CASING. (B) AN INERTIA PUMP SCHEMATIC ALSO TRUNCATED TO SHOW DETAILAND THE FILTER AT THE BOTTOM OF THE CASING. THE PUMP IS MADE OF TUBING AND A SMALL CHECK VALVE WRAPPED IN ELECTRICAL TAPE THAT FORCES WATER TO FLOW UP THE INNER TUBING AND OUT OF THE WELL. 
Finally, the hole around the pipe was filled with locally harvested clay and tightly packed. Cement was to be poured around the casing at the surface in order to prevent surface water from contaminating the aquifer below. A hand-pump was designed and construction was left for later completion.

\section{Water Testing}

We tested water from existing wells, stored drinking water, the local river, and our pilot well for chemical and biological contaminants. This testing gauged the quality of existing water sources and ensured that groundwater access established by the project was safe to drink.

The chemical contaminants tested for were nitrate, nitrite, $\mathrm{pH}$, and total \& free chlorine. Nitrates and nitrites indicate contamination by agricultural runoff, since their primary source in rural environments is from fertilizers. ${ }^{\mathrm{xx}}$ The free and total chlorine tests indicate efficacy of water treatment processes using chlorination. ${ }^{\text {xxi }}$ We used test strips purchased from Hach ${ }^{\circledR}$ to evaluate the levels of these contaminants. The nitrate and nitrite tests measured a range of 0-50 $\mathrm{mg} / \mathrm{L}$ and $0-3 \mathrm{mg} / \mathrm{L}$ respectively, while the free and total chlorine tests measured a range of 0-10 $\mathrm{mg} / \mathrm{L}$. $^{\mathrm{xxvii}}$

Our biological tests measured total Coliform and E. coli. Because testing for specific pathogens is expensive and not feasible for field water testing, we followed the common practice of using indicator organisms, which are easier and cheaper to test for but helpful because they usually occur concurrently with disease-causing microbes. Coliform is a commonly occurring bacteria, whereas $E$. coli come from animal or human excreta and their presence indicates possible contamination of the water source. ${ }^{\text {xxviii }}$

Our water testing method was developed at the MIT Development Labs. ${ }^{\text {xxix }}$ The tests gave us counts of the number of colonies per $100 \mathrm{~mL}$ of sample. This method differs from conventional coliform membrane filter tests in that it was developed to be a low-cost method for use in developing countries, where electricity to power an incubator, for example, might not be available. With this method, water collected aseptically is placed in a sterile container and is pulled via a vacuum through a 0.45 micron filter. Microorganisms are caught against the filter, which is placed in m-ColiBlue24 media and incubated for 24 hours. This method uses an incubator that employs phase change media rather than electricity to keep samples at 35 degrees Celsius. The phase change media is solid at room temperature; it is heated until the solid material liquidizes. The phase change media is placed in a cooler and maintains its temperature for 24 hours. After 24 hours, the samples were removed from incubation and the number of distinct colonies was counted based on color, with blue colonies representing E. coli, and the addition of pink and blue colonies representing Total Coliform. Bottled water was used as a control, and each water sample was tested in duplicate.

\section{Well Assessment}

Slug testing was used to determine the hydraulic conductivity $K$ of the aquifer following casing and initial conditioning. Hydraulic conductivity, a factor in Darcy's law, is the measure of rate by which water passes through the soil at a given head gradient ${ }^{\mathrm{xxx}}$. Several methods for estimating $K$ exist. The difference between these methods is considered to be small compared to the spatial variability of $K$. Therefore, the Hvorslev method, which allows for most common well configurations, was used to determine the horizontal conductivity $\left(K_{h}\right) .{ }^{\mathrm{xxx} \text { xxxii }}$ 
We used the inertia pump (Figure 4B) to remove water from the well until it was empty. The rate at which the water refilled the casing was measured by slowly lowering the inertia pump tubing into the well and attempting to pump out water at gradually lower levels. Water in the bottom of the inertia pump could be heard once the water level was reached; the amount of tubing outside the casing was recorded, and subtracted from the total length of the tubing, in this way we determined the water level. Equation 1, was used to calculate the hydraulic conductivity. Here $d$ is the diameter of the well, $t$ is time, and $\Delta h$ is the distance from the water level at time $t$ to the static head level in the well:

$$
K_{h}=F \frac{d}{t_{2}-t_{1}} \ln \left(\frac{\Delta h_{1}}{\Delta h_{2}}\right)
$$

The pre-factor $F$, calculated using equation 2 below, is an adjustment factor based on the well's geometry, where our well has a filter of height $L$. This equation assumes the soil above the filter is permeable as in an unconfined aquifer. Here, $m$ is the square root of the ratio of the horizontal to vertical hydraulic conductivity; we assumed this value to be 1 within the aquifer.

$$
F=\frac{d}{8 L} \ln \left[\frac{2 m L}{d}+\sqrt{1+\left(\frac{2 m L}{d}\right)^{2}}\right]
$$

\section{RESULTS}

\section{Hydro-geological Survey}

Five pre-existing, privately owned wells were found in the region (Figure 5), none of which dry up over the course of the year. Of them, three had been drilled by companies hired at a high fee and two were dug by hand, and one of which was completed following our initial assessment trip. None of the wells were covered and none produced potable water. In general, we found that the head in the wells was around 5-15 m below the ground, which encouraged us to conduct our manual percussion drilling project in the hopes of finding a shallow water table at our well site. One $18 \mathrm{~m}$ deep artesian well (Alejandro's well) was found closest to our site suggesting a potential confined aquifer in the area and a high hydraulic conductivity for the surrounding soil. 


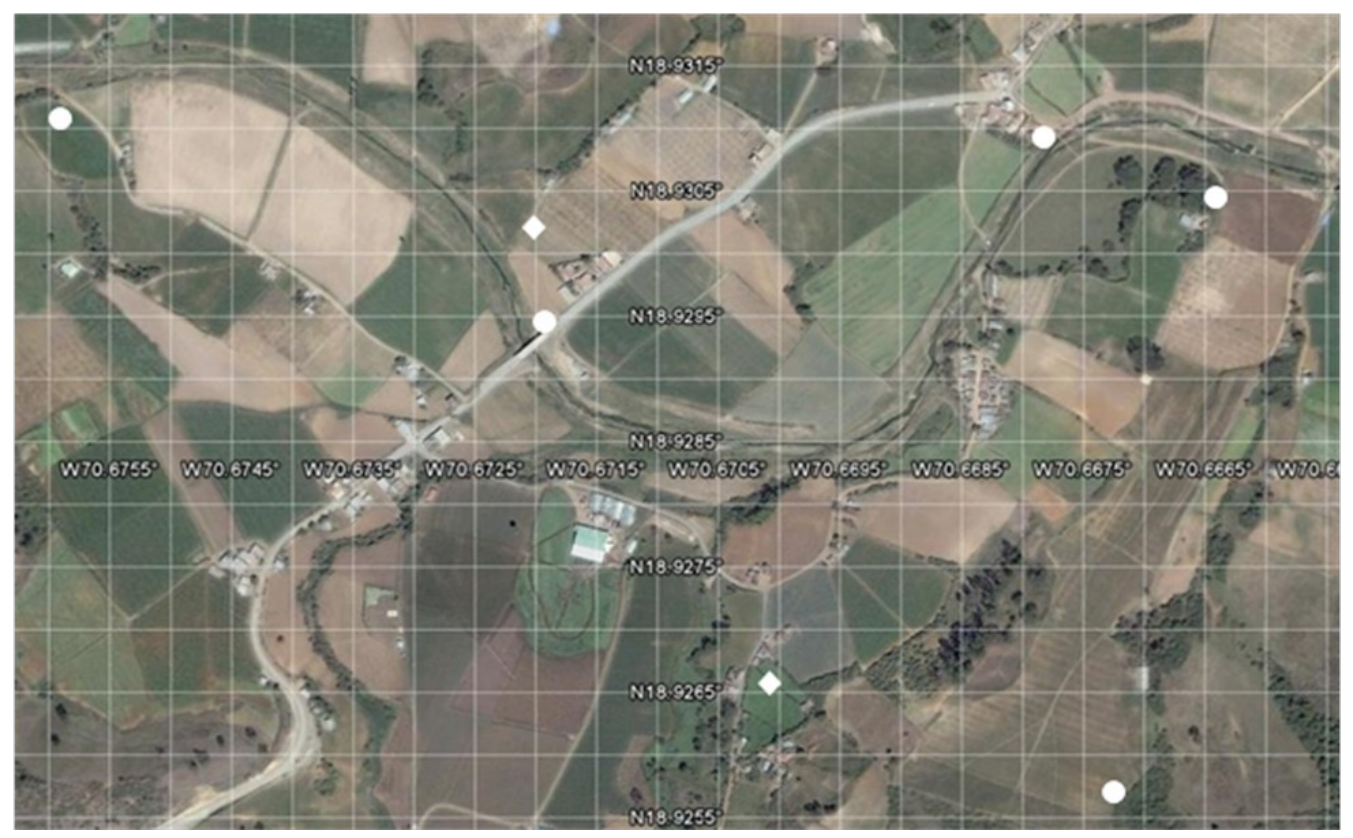

FIGURE 5

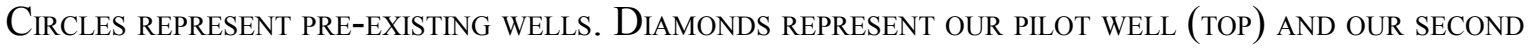
ATTEMPT WHICH WE WERE UNABLE TO FINISH DUE TO TIME CONSTRAINTS (BOTTOM). THE IMAGE WAS TAKEN from Google Earth software, 2009 Digital Globe $\mathcal{C}$, image date was March 20, 2006. The grid is MEASURED IN DECIMAL DEGREES. THE AVERAGE RIVER ELEVATION WITHIN THIS REGION WAS MEASURED WITH GPS AS 1213 M, WhILE OUR PILOT WELl SITE WAS AT AN ELEVATION OF 1219 M.

The resistivity results were plotted along with the simulated results from the document on groundwater XVII for two situations described in the schematic below. These comparison plots were obtained experimentally and they were chosen because of their relevance to our plot.

Our resistivity results (Figure 6) corresponded most closely with comparison 1 (top right schematic), which suggested that the ground had a soil layer, below which was a weathered basement, for example an undifferentiated layer of metamorphic and igneous rock, then a firm basement. However, during drilling it was possible to qualitatively evaluate the types of soil we were drilling through and this was recorded into our drilling log. We drilled through the initial layer of top soil, then reached red clay with gradually more sand content, and finally at approximately $7.1 \mathrm{~m}$ we reached a more coarse gray sand. This data suggests that the ground conditions more closely resembled that of comparison 2. Both comparisons did however suggest that for the first approximately $10 \mathrm{~m}$ the ground contained only unconsolidated material, which led us to pursue manual drilling and was accurate compared to what we found.

In order to evaluate our data and determine possible sources of error, we used the fact that, among other things, the resistivity is inversely proportional to the water content. ${ }^{\text {xxxiii }}$ This suggests that the soil in the region we drilled in possibly had more water than the soil for which the comparisons are drawn. Systematic errors due to poor electrode contact with the ground and noise may also have occurred, and in the future could be reduced by conducting replicated and reciprocal (positive and negative current and potential electrodes reversed) measurements. ${ }^{\text {xxiv }}$ In 
addition, continuing to use this method and recording actual ground conditions will provide useful experimental comparisons specific to the area that can be used in the future.
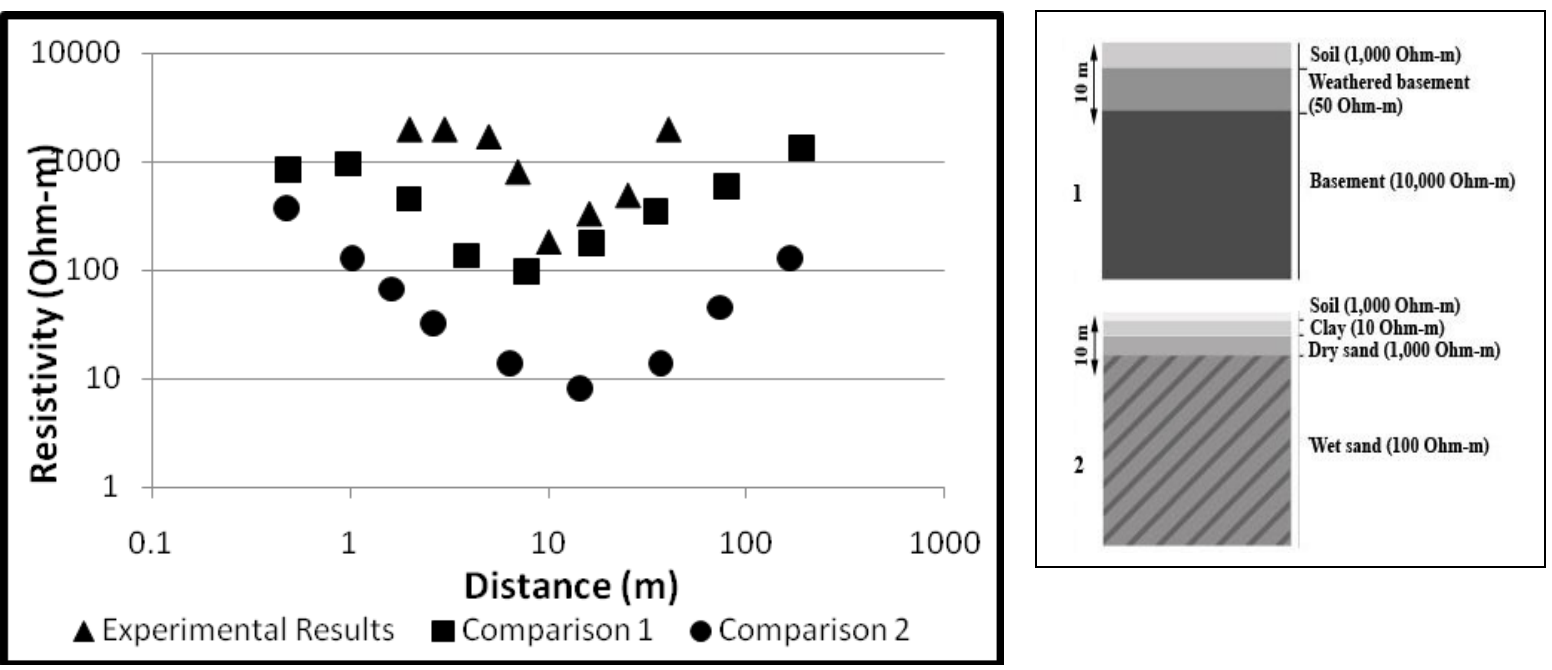

FIGURE 6

COMPARISON OF TWO-DIMENSIONAL RESITIVITY SURVEY RESULTS WITH THEORETICAL DATA ${ }^{\text {xxxv }}$. THE VALUES OF RESISTANCE OBTAINED FROM THE SURVEY WERE MULTIPLIED BY A GEOMETRIC FACTOR K TO OBTAIN VALUES OF RESISTIVITY, WHICH IS PLOTTED AGAINST POTENTIAL ELECTRODE SEPARATION. THEORETICAL GROUND CONDITION SCHEMATICS REPRESENT COMPARISON 1 (TOP RIGHT) AND COMPARISON 2 (BOTTOM RIGHT).

\section{Drilling Performance}

After several drill-bit designs and experimentation with two slightly different bits, we found that several factors were important for successful drilling performance with the WFAI drill bit. Most importantly, the maximum diameter of the wings needed to be smaller than the outer diameter of the bottom coupling they rested against. This meant that the drilling hole was only as wide as the bottom coupling, so that when the drilling stem was dropped, more fluid was forced into pipe, to be ejected. The thick walls of the high pressure couplings helped provide a solid surface for the wings to make contact on. The wings themselves on the bit were kept sharp, and were cut at a fairly acute angle. This allowed for easier penetration into the ground, particularly against rocks. The truncated cone on the top of the bolt produced a good seal that prevented drilling fluid from leaking through the valve on the upstroke.

Based on our drilling log, we were able to drill 9.1 meters in a cumulative 3 hours and 56 minutes. This total time reflects only how long the drilling rig operation took, and not preparation time. Including preparation time, the drilling process took 2 days. The upper layers of the soil were composed primarily of clay, where we reached drilling speeds of $\sim 6 \mathrm{~cm} / \mathrm{min}$. When we hit a thin consolidated layer, possibly rock, our drilling rate slowed to $\sim 0.3 \mathrm{~cm} / \mathrm{min}$. When gray, large grained sand was reached at a depth of $7.1 \mathrm{~m}$, a rate of $\sim 20 \mathrm{~cm} / \mathrm{min}$ was reached. This high variability in drilling speed is to be expected with manual drilling techniques.

\section{Well Conditioning}


In retrospect, the pressure produced by back-pumping with the motorized water pump may have adversely effected the formation around the filter, and increased the time required to condition the well during the inertial pumping and swabbing stage of conditioning. During this time, dark gray sand was continually removed from the formation, but the well only began to recharge after 1.5 days. Conditioning continued for 2.5 days in total, longer than the drilling process took. We had not expected the conditioning to take this long; however, we were later advised by WFAI that some wells drilled using the WFAI method are abandoned as "dry" too early from lack of conditioning.

A hand-pump was designed and construction was started. Future steps include designing a simple reciprocating plunger pump, building a proto-type, and testing it for flow performance. A reciprocating plunger pump is a two-valve pump separated by an inner streaming tube. The inner tube is inserted into the well casing with a check valve at the bottom. Inside the tube, a one-way plunger acts as the second valve, pulling water up through the check valve and into the tube on the up-stroke via suction, but forcing water through the plunger on the down-stroke. This type of hand pump is the most common type of displacement pump ${ }^{\mathrm{xxxvi}}$ and is ideally suited for small diameter wells that inhibit, both physically and economically, the use of larger more costly pumps.

\section{Water Testing}

The table below shows the results of our water tests. We tested drinking water from a storage container of one of the local community members, water from the nearby Rio Tireo, water from several pre-existing wells in the area, and the water from the pilot well we drilled. Due to time constraints, we were not able to obtain biological data for our pilot well, as the test required twenty-four hours and we completed the well on the last day of the trip.

\section{TABLE I}

This table SHOWS Results From testing local SOURCeS OF WATER. THE DRINKING WATER SAMPLE WAS From A SMALL STORAGE CONTAINER BUT IT WAS ORIGINALLY COLLECTED FROM A SMALL STREAM, THE RIVER WATER IS from the Rio Tireo, Well 1 AND Alejandro's well correspond to PRE-Existing WELLS, and the

Pilot Well is the well that we drilled during this Study. These Water sources were tested for NITRATES, NITRITES, PH, TOTAL AND FREE CHLORINE, AND TOTAL COLIFORM AND E. COLI.

\begin{tabular}{|c|c|c|c|c|c|c|c|}
\hline Location & $\begin{array}{l}\text { Nitrite } \\
(\mathrm{ppm})\end{array}$ & $\begin{array}{c}\text { Nitrate } \\
\text { (ppm) }\end{array}$ & pH & $\begin{array}{c}\text { Free } \mathbf{C l}_{2} \\
\text { (ppm) }\end{array}$ & $\begin{array}{c}\text { Total } \mathrm{Cl}_{2} \\
\text { (ppm) }\end{array}$ & $\begin{array}{c}\text { Coliform (\# } \\
\text { colonies } / 0.1 \mathrm{~L})\end{array}$ & $\begin{array}{c}\text { E coli (\# } \\
\text { colonies } / 0.1 \mathrm{~L})\end{array}$ \\
\hline $\begin{array}{c}\text { Drinking Water } \\
\text { Sample }\end{array}$ & 0 & 0 & 7.5 & 0 & $\overline{0}$ & 188 & 106 \\
\hline River Water & 0 & 4 & 7.2 & 0 & 0 & TMTC & 30 \\
\hline Well 1 & 0.1 & 5 & 7.8 & - & - & 150 & 10 \\
\hline Alejandro's Well & 0 & 5 & - & - & - & 15 & 13 \\
\hline Pilot Well & .05 & .5 & 7.8 & 0 & 0 & - & - \\
\hline
\end{tabular}


These results indicate that the drinking water, the river water, and Alejandro's well, are contaminated biologically due to the presence of E. coli in the results. E. coli come from animal or human feces, so their presence indicates the likely presence of other pathogens in the water source. Potable water should be free from any E. coli in the test results. ${ }^{\text {xxvii }}$ The high level of coliform and E. coli in the drinking water sample clearly shows the need for a clean water supply in this region. The level of biological contamination in the Alejandro's well is thought to be due to poor maintenance and protection rather than groundwater contamination: the well sits in a low lying catchment area for stagnant water and remains uncovered.

The zero readings for total and free chlorine are not surprising given that the water was not being disinfected. However, note that the chlorine readings for our pilot well were taken after we added bleach to the well for disinfection, showing that we did not contaminate the aquifer in doing so. Bleaching wells before sealing is common practice in North America, as an added precaution against contamination during the drilling process. The bleach is thought to oxidize very quickly at such low concentrations. ${ }^{\text {xxxiii }}$

While nitrates were found in the river water and the wells, they were within safe drinking water limits. The World Health Organization (WHO) guideline values for nitrites and nitrates in drinking water are $3 \mathrm{mg} / \mathrm{L}$ and $50 \mathrm{mg} / \mathrm{L}$ respectively, ${ }^{\text {xxix }}$ so while there are small amounts of nitrate and nitrite in our pilot well, these levels are potable based on the WHO guideline values.

\section{Well Assessment}

Using equations (1) and (2) the average hydraulic conductivity was determined to be $1.8 \times 10^{-4}$ $\mathrm{cm} / \mathrm{s}$. This is within the range for the expected values in clean sand $10^{-4}-10^{0} \mathrm{~cm} / \mathrm{s}$. ${ }^{\text {xlxli }}$ Our low value was likely due to the necessity for continued conditioning of the well; this hypothesis is based on the WFAI mentor's experience using high flow rate back-pumps. It took 1.5 days of conditioning before the well would recharge on its own, likely due to the excessive backpumping with a motorized pump disturbing the formation around the filter. In a further day of conditioning we were able to increase the head level to $4.5 \mathrm{~m}$ which is where we anticipated the water table to be. With more time, it is likely that the recharge rate could have also been improved. Another possibility for the low calculated hydraulic conductivity is the increased resistance from the potato sack we selected as a filter, which in hindsight may have been too fine, preventing high recharge rates. Potato sacks of varying permeability were available in the region and samples were brought back for future testing.

\section{Community Involvement \& Education}

In the process of drilling our first successful well, we found that the excitement about the project among the local community motivated many of them to volunteer their help. During the drilling process, members of the family of all ages consistently did their share to help out, whether they were pulling the handle to lift the drill bit and pipe, helping keep the bore hole full of mud, or making sure the excess water expelled during drilling drained properly. At times, it was very clear that the community had learned the method for themselves, taking the initiative to keep drilling while we took a break. They also took turns conditioning the well and pumping out the preliminary sandy water.

In addition to this help, each day there was a large group watching our progress, curious about our methods and always offering tips they felt might help. We were frequently impressed 
by the parts that they fashioned out of everyday materials, which we might have needed a trip to the hardware store in order to produce. Everyone was enthusiastic to learn about the project and undersood the potential for future drilling in the area. Many people requested to have a well drilled on their property. Further evidence of this enthusiasm was a small hand-dug well which was attempted in the community between the May 2008 and January 2009 trips. Although this well had been abandoned because it did not produce a high enough yield for the local family because it was not deep enough, it proved that the community was willing to solve their water supply problem and needed a developed technique for drilling family-sized wells.

Not only were we teaching the community new ideas, but they were doing the same for us. Actually building the drilling-rig and constructing the well ourselves provided the opportunity for important lessons in logistics, a broad problem that plagues many international development projects. A lot of design ideas seem ideal from a desk in Cambridge, but actually implementing them on the ground brings in many other dimensions that often are not considered such as the cost, specification, and availability of local materials. This project gave our group a strong lesson in the importance of these details. Many of these lessons were learned from our local partners who, although not familiar with our drilling technique, provided valuable insight into the on-theground practical problems we faced throughout these trips.

Following the completion of this pilot well, HCEWB is deciding how to proceed with a longterm project. The decision making process includes re-evaluating family-sized wells as a solution to the water supply problem in Tireo Abajo to determine if it is in fact the best solution for the community. Professional and Peace Corps mentors are playing more of a role in the project's direction in order to assist in developing a sustainable project. HCEWB has unanimously decided that education, both on water storage and procurement methods, should be a larger component of the group's work in the future. We feel that the rapport built with the local community members on earlier trips will aid in this endeavor.

\section{Project Sustainability}

The document II on sustainability provides a matrix to evaluate the sustainability of a project. The factors they refer to in this matrix are: sociocultural respect, community participation, political cohesion, economics sustainability, and environmental sustainability. Sociocultural respect attempts to integrate the project within the fabric of the society, community participation aims to foster local ownership, and political cohesion refers to the political environment in which the project takes place, and together, these three factors define the social sustainability of a project. Regarding our implementation, we evaluate that it had the characteristic of being socioculturally respectful, since other people in the region already use wells to obtain water. In addition, the ownership of our well-drilling project has been transferred to the community and the community leaders approved our initiative. This is thus a socially sustainable project provided the community members carry on with it. Concerning economic sustainability, drilling wells by the WFAI method costs about $1 / 20$ th the price of mechanical traditional, mechanical methods, and is consequently much more financially viable for individual families. The drilling process of small, individual wells itself does not involve the degradation of the environment. Taking these into account, we are confident that the individual wells we proposed to be drilled in the community of Tireo Abajo by the WFAI constitute a sustainable project if implemented properly. 


\section{DISCUSSION}

In the implementation of our pilot project, we found that the WFAI method for drilling small wells was highly adaptable to conditions in the region of Constanza in the Dominican Republic. The geophysical conditions indicated the presence of a shallow water table in the river valley where members of the community of Tireo Abajo live. The presence of sand and clay, with little rock ensured that drilling proceeded at a reasonable rate, with reduced risk of reaching an impenetrable layer and being forced to abandon the borehole. The method demonstrated that it is possible to access what preliminarily seems to be a clean groundwater source in this region. Located in a receptive community that is open to learning about the drilling method and excited to implement it, we feel that with additional trips to the area the method will eventually be able to become self-perpetuating so that many families and future generations will be able to attain potable water.

Although this method has many practical benefits, it also has inherent limitations that must be considered throughout the drilling and construction process. As is the case with any drilling process, the WFAI method is high risk in that it is subject to many uncertainties. The nature of this method requires not only the knowledge of how to drill, which we believe to be straightforward to someone who has participated in the process, but also, the potentially more difficult ability to understand hydrological principles. The WFAI drilling method should be treated as the small-scale method it is. While it is suitable for providing water to fulfill families' needs, it must be considered in this light: it cannot quickly alleviate the need of an entire community. The WFAI method does have the advantage that due to its cheap implementation, individual community members are able to take charge of their own water supply, rather than depending on external help to gain access to clean water. We seek to continue to explore this method and others into the future, hoping to eventually pass it to community leaders as part of a long-term project that aims to entirely satisfy community needs.

\section{REFERENCES}


International Journal for Service Learning in Engineering

Vol. 5, No. 1, pp. 128-147, Spring 2010

ISSN 1555-9033

' UNICEF/WHO (2008). Progress on Drinking Water and Sanitation. UNICEF and WHO, Geneva, Switzerland

ii Jennier R. McConville and James R. Mihelcic, “Adapting Life-Cycle Thinking Tools to Evaluate Project Sustainability in International Water and Sanitation Development Work," Environmental Engineering Science, vol. 24, no. 7 (2007), 937948.

iii Charles R. Fitts, Groundwater Science, (Amsterdam, Boston: Academic Press, 2002).

iv Sally Sutton, Preliminary Desk Study of Potential For Self-Supply in Sub-Saharan Africa: For WATERAID and the Rural Water Supply Network, SWL Consultants, UK (2004).

${ }^{v}$ Maggie A. Montgomery, Jamie Bartram, and Menachem Elimelech, Perspective, Environmental Engineering Science, Vol. 26, No. 5 (2009), 1017-1023.

vi Bob Elson and Rod Shaw, "Simple Drilling Methods", Waterlines, Vol. 13 No. 3 (1995), 15-18.

vii Arjen van der Wal, Understanding Groundwater \& Wells in Manual Drilling, PRACTICA Foundation, Delft, The Netherlands (2008).

viii Elson and Shaw, "Simple Drilling Methods."

ix Elson and Shaw, "Simple Drilling Methods." .

${ }^{x}$ van der Wal, Understanding Groundwater \& Wells in Manual Drilling.

${ }^{x i}$ Terry Waller, "Water For All International”, http://waterforallinternational.org/default.aspx

xii Kerstin Danert, "Realizing the Potential of Hand-Drilled Wells for Rural Water Supplies,” Waterlines, Vol. 28 No. 2 (2009), 108-129.

xiii Terry Waller, "Water For All International”, http://waterforallinternational.org/default.aspx

xiv Danert, "Realizing the Potential of Hand-Drilled Wells for Rural Water Supplies."

xv Waller, "Water For All International", http://waterforallinternational.org/default.aspx.

xvi Guy Howard, ed., Water Supply Surveillance: A Reference Manual, Water, Engineering, and Development Centre, Loughborough University, UK (2002).

xvii Alan M. MacDonald, Group Intermediate Technology Development, Knowledge Great Britain Dept. for International Development. Developing Groundwater: A Guide for Rural Water Supply, (Bourton-on-Dunsmore, Warwickshire: ITDG Pub., 2005).

xviii A. Samouëlian, I. Cousin, A. Tabbagh, A. Bruand, G. Richard, "Electrical Resistivity Survey in Soil Science: a review," Soil and Tillage Research 83, (2005), 173-193.

${ }^{x i x}$ MacDonald et al., Developing Groundwater : A Guide for Rural Water Supply.

${ }^{x x}$ Samouëlian et al, "Electrical Resistivity Survey in Soil Science: a review," 173-193.

${ }^{\text {xxi }}$ van der Wal, Understanding Groundwater \& Wells in Manual Drilling.

xxii Terry Waller, Baptist Well Drilling in Bolivia: An alternative to expensive well drilling, designed for the poor to do it themselves (2004). (An operations manual available upon request from Terry Waller "Water For All International", http://waterforallinternational.org/default.aspx.)

xxiii Waller, Baptist Well Drilling in Bolivia: An alternative to expensive well drilling, designed for the poor to do it themselves.

xxiv Rðb Musci, personal communications with corresponding authors, April 2009.

${ }^{x x v}$ WHO, Guidelines for Drinking Water Quality (Geneva: World Health Organization, 2006).

xxvi Howard, ed., Water Supply Surveillance: A Reference Manual.

xxvii "Nitrate/nitrite and 5-in-1 test strips," access at http://www.hach.com.

xxviiic"Nitrate/nitrite and 5-in-1 test strips."

xxix Chandalia, J. et al., Low-Cost Water Testing Apparatus, Design that Matters (2004).

${ }^{x x x}$ Randall J. Charbeneau, Groundwater Hydraulics and Pollutant Transport (Long Grove, IL: Waveland Press, Inc., 2006). 
${ }^{x x x i}$ Fitts, Groundwater Science.

xxxii Charbeneau, Groundwater Hydraulics and Pollutant Transport.

xxxiii Fitts, Groundwater Science.

xxxiv Samouëlian et al, "Electrical Resistivity Survey in Soil Science: a review."

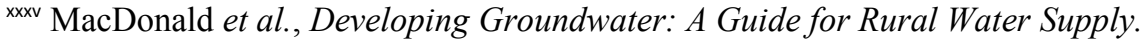

xxxvi Edmund G. Wagner and Joseph N. Lanoix, Water Supply for Rural Areas and Small Communities, (Geneva: World Health Organization, 1959).

xxxvii WHO, Guidelines for Drinking Water Quality.

xxxviii Rob Musci, personal communications with corresponding authors, April 2009.

${ }^{\text {xxxix }}$ WHO, Guidelines for Drinking Water Quality.

${ }^{\mathrm{xl}}$ Fitts, Groundwater Science.

xli Charbeneau, Groundwater Hydraulics and Pollutant Transport 